Матвиенко М. В., Квасницкий В. Ф., Макаренко Н. А.

\title{
ВЛИЯНИЕ ПРЕДЕЛА ТЕКУЧЕСТИ ПРОСЛОЙКИ НА НАПРЯЖЕННО-ДЕФОРМИРОВАННОЕ СОСТОЯНИЕ УЗЛОВ ПРИ ДИФФУЗИОННОЙ СВАРКЕ И ПАЙКЕ ЖАРОПРОЧНОГО СПЛАВА С УЧЕТОМ ПЛАСТИЧЕСКИХ ДЕФОРМАЦИЙ МАТЕРИАЛОВ ПРИ БЫСТРОМ ОХЛАЖДЕНИИ
}

Диффузионная сварка (ДС) и пайка являются основными способами соединения литейных жаропрочных сплавов, которые практически не свариваются плавлением, но имеют также свои проблемы, связанные с пластической деформацией для образования физического контакта, активацией соединяемых поверхностей, а также развитием диффузии и рекристаллизации в зоне стыка. Для решения этих проблем применяют ДС с промежуточными прокладками $[1,2]$ в том числе пайку или TLP-соединение [3]. При ДС обычно используют фольгу из пластичного металла, а при пайке роль промежуточной прокладки играет припой, который может иметь разные физико-механические свойства (ФМС) как до пайки, так и после взаимодействия с основным материалом. В таких соединениях в сварной или паяный шов вводятся второй при соединении однородных или третий при соединении разнородных металлов. Наличие таких прослоек изменяет характер напряжено-деформированного состояния в зоне стыка, что было установлено аналитически еще в 20-м веке О. А. Бакши [4]. Развитие компьютерной техники и программных комплексов позволяет моделировать напряжённо-деформированное состояние (НДС) соединений с учетом практически всех действующих факторов и динамики процессов $[5,6]$. Формирование объемного напряженного состояния может существенно влиять на работоспособность сварных и паяных узлов. В связи с этим необходимо критически относиться к различным оценкам работоспособности соединений и узлов, если они даны без учета их НДС. Поэтому данная работа является актуальной.

Большой вклад в развитие теории и методов моделирования НДС узлов, а также оценки остаточного ресурса конструкций внес академик НАН Украины, доктор, технических наук, профессор Владимир Иванович Махненко [7].

Анализ последних достижений и публикаций. Начало исследований особенностей формирования НДС соединений разнородных и однородных материалов с промежуточными прослойками было положено академиком НАН Украины В.И. Махненком, что позволило разработать технологию ДС с управляемым НДС [8]. Моделирование НДС при пайке металлов с графитом рассмотрено в работе [9], а НДС сварных и паяных узлов из однородных металлов с мягкой прослойкой при осевой нагрузке рассмотрено в работе [10]. Влияние толщины промежуточной прослойки и ее жесткости на НДС узла в состоянии упругости исследовано в работе [11]. Учитывая высокие температуры ДС и пайки жаропрочных сплавов нельзя оставлять без внимания также роль пластических деформаций.

Цель работы-исследование влияния пластических деформаций на формирование НДС узла цилиндр-цилиндр при быстром охлаждении после ДС или пайки.

Основной материал исследования

Исследование влияния режима охлаждения и сочетания свойств прослойки и основного металла проводились на цилиндрических моделях (рис. 1), при толщине прослойки 0,08 мм. Исследовалось НДС узлов при термическом нагружении снижением температуры от 1270 до $1100{ }^{\circ} \mathrm{C}$ с большой скоростью (без учета ползучести).

Свойства основного металла, кроме предела текучести во всех вариантах принимались одинаковыми, постоянными при температуре $1100 \ldots 1270{ }^{\circ} \mathrm{C}$ как после термообработки: $1180{ }^{\circ} \mathrm{C} \times 2$ часа $+1265^{\circ} \mathrm{C} \times 2$ часа /охлаждение на воздухе $+1050{ }^{\circ} \mathrm{C} \times 4$ часа /охлаждение на воздухе): 
модуль упругости $E_{o м}=0,5 \cdot 10^{5} \mathrm{MПа,} \mathrm{коэффициент} \mathrm{Пуассона} \mu=0,4$, коэффициент упрочнения при пластическом деформировании материала $\kappa_{n л}=0,5 \cdot 10^{2} \mathrm{Mпа;}$

коэффициент линейного термического расширения КЛТР $=21 \cdot 10^{-6} 1 /$ град. предел текучести (условный) $\sigma_{0.2}$ принят линейно уменьшающимся от 150 МПа при $1100{ }^{\circ} \mathrm{C}$ до 0 при температуре $1270{ }^{\circ} \mathrm{C}$.

Исследовались варианты узлов с прослойками толщиной 0,08 мм, имеющими КЛТР меньше в 2 раза $\left(10,5 \cdot 10^{-6} 1 /\right.$ град, варианты 1 и 2) и больше в 2 раза $\left(42 \cdot 10^{-6} 1 /\right.$ град, варианты 3 и 4) по сравнению с основным металлом;

пределом текучести - 0,85 (вар. 1 и 3) и 0,7 (вар. 2 и 4) от предела текучести основного металла, при коэффициенте Пуассона 0,4 .

Модуль упругости материала прослойки во всех вариантах принимался одинаковым с основным металлом $E_{n p}=0,5 \cdot 10^{5}$ МПа.

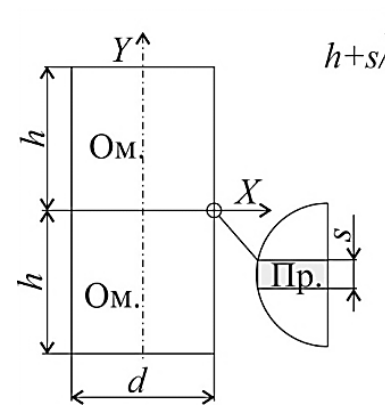

a

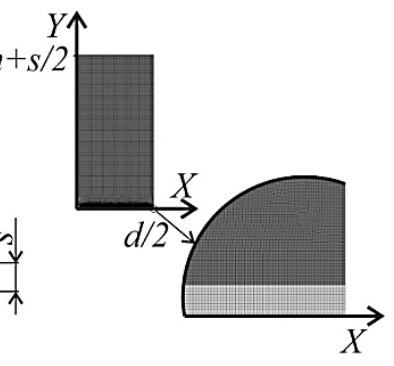

6

B

Рис. 1. Общий вид образца с прослойкой (а), сечение конечно-элементной модели (б) и зона сопряжения прослойки с соединяемым металлом (в)

Термическое нагружение производилось снижением температуры с большой (без учета ползучести) скоростью остывания. Учитывалась возможность пластического деформирования как прослойки, так и основного металла по условию Мизеса.

Анализ полей всех составляющих и эквивалентных напряжений показал, что так же, как и в упругой стадии деформирования, на большей части узла напряжения отсутствуют, и только в небольшой зоне, расположенной вблизи прослойки у кромки стыка (у внешней поверхности цилиндра), и в самой прослойке создается сложное НДС, обусловленное разностью КЛТР соединяемого металла и прослойки.

Сравнение полей узлов с аналогичными полями варианта с нейтральной прослойкой в упругой задаче [11] показало их практически полное совпадение в вар. 1. Это объясняется очень малой величиной пластических деформаций в узлах с прослойками с пределом текучести, близким к таковому для основного металла (на $15 \%$ ниже). Разность КЛТР прослойки и основного металла в $10,5 \cdot 10^{-6} 1 /$ град при линейном снижении температуры на 170 град (с 1270 до 1100 град) и таком же линейном увеличении предела текучести в этом варианте создает напряжения, достигающие предела текучести. В результате заметные пластические деформации, превышающие $0,015 \%$, возникают только в очень малой зоне, соизмеримой с толщиной прослойки, прилегающей к внешней поверхности узла.

При снижении предела текучести прослойки еще на 15 \%, до 0,7 предела текучести основного металла (вар. 2), пластические деформации в прослойке увеличиваются по всему ее сечению. Соответственно изменяются и поля напряжений. При сохранении характера распределения несколько снижается уровень всех напряжений. Пластические деформации мало влияют на характер полей НДС, изменяя только уровень напряжений.

Пластические деформации при всех вариантах сочетания пределов текучести прослоек и основного металла отсутствуют в основном металле, где эквивалентные напряжения ниже его предела текучести. Они сосредоточены только в материале прослойки. Величина пластических деформаций растет с уменьшением предела текучести прослойки и увеличением разности КЛТР прослойки и основного металла. 
Анализ распределения напряжений вдоль стыка по эпюрам (рис. 2...5) показывает, что все составляющие и эквивалентные напряжения в основном металле отсутствуют на большей части стыка и только в небольшой зоне вблизи наружной поверхности, протяженностью около 1 мм, они появляются и резко возрастают.

Радиальные напряжения в основном металле - растягивающие в вар. 1 и 2 и сжимающие в вар. 3 и 4 (рис. 2, а). Оставаясь близкими к нулю на большей части стыка, они достигают у кромки стыка максимальной величины около 65 и - 100 МПа в вар. с прослойками с малым (вар. 1 и 2) и большим (вар. 3 и 4) КЛТР, соответственно. При упругом деформировании аналогичных узлов с прослойкой с малым КЛТР максимальные напряжения достигают 75 МПа.
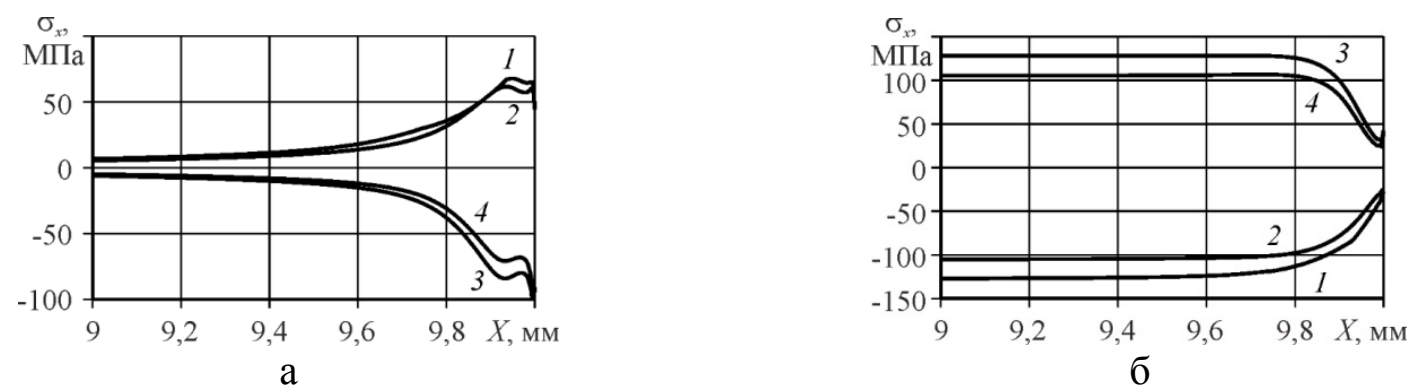

Рис. 2. Эпюры радиальных напряжений по стыку в основном металле (а) и прослойке (б) вблизи ее наружной кромки, варианты 1, 2, 3 и 4

В материале прослойки радиальные напряжения сжимающие в вар. 1 и 2 и растягивающие в вар. 3 и 4 (рис.2,б). На большей части стыка они на уровне около - 128 и -105 МПа (вар. 1 и 2) и 128 и 105 МПа (вар. 3 и 4), то есть одинаковы по величине в узлах с прослойками с малым и большим КЛТР. При этом их уровень снижается пропорционально пределу текучести прослойки в момент окончания охлаждения (120 и 112 МПа при 1100 град) и несколько превышает его за счет упрочнения при пластическом деформировании.

У кромки стыка (рис. 2, б) радиальные напряжения заметно уменьшаются до \pm 30 МПа (более, чем в 3 раза) во всех вариантах.

Аналогично радиальным распределены и окружные напряжения.

В прослойке осевые и касательные напряжения также отсутствуют на большей части длины стыка (рис. 3) и только вблизи кромки появляются и резко возрастают, осевые напряжения до 68 и 55 МПа в вар. 1 и 2 и -69 и -59 МПа в вар. 3 и 4, а касательные до -44 и -38 МПа и 51 и 43 МПа соответственно.
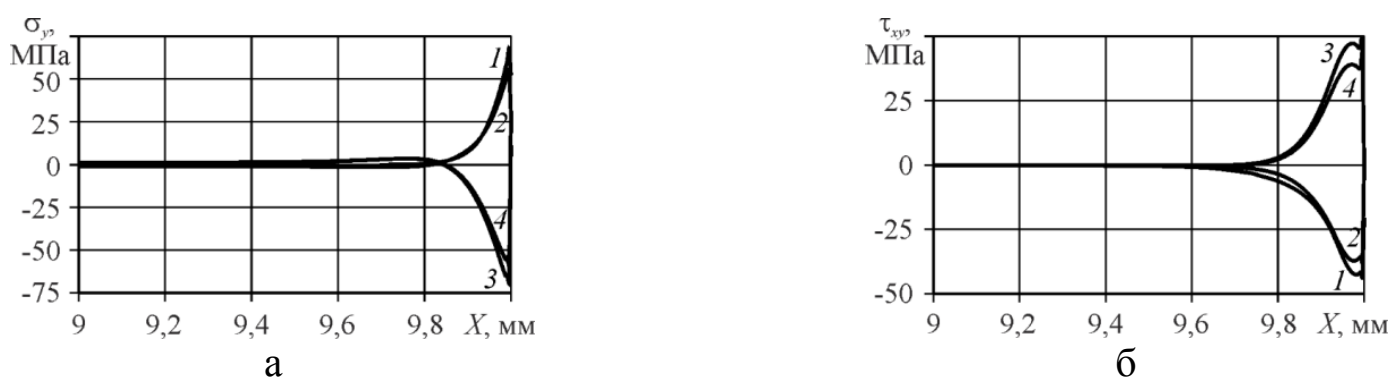

Рис. 3. Эпюры осевых (а) и касательных (б) напряжений по стыку основного металла и прослойки вблизи его кромки в вариантах 1, 2, 3 и 4

В соответствие со всеми составляющими напряжениями распределены и эквивалентные (рис. 4). Как в соединяемых материалах, так и в прослойке во всех вариантах на большей части ширины узла сохраняется постоянный уровень напряжений. При этом в основном металле они практически равны нулю с изменением только в небольшой зоне у кромки стыка. Здесь они резко возрастают, достигая 76 и 67 МПа (вар. 1 и 2) и 87 и 72 МПа (вар. 3 и 4) 
и оставаясь ниже его предела текучести (150 МПа). При упругом деформировании аналогичных узлов они составляют 100 и 200 МПа в узлах с прослойками с малым и большим КЛТР соответственно. Пластические деформации материала прослойки снижают эквивалентные напряжения в наиболее загруженной зоне основного металла, разгружая и предотвращая пластические деформации в нем.

В прослойке эквивалентные напряжения на большей части длины стыка заметно снижаются по сравнению с упругим деформированием и остаются на постоянном уровне 127 (вар. 1 и 3) и 105 МПа (вар. 2 и 4), близком к пределу текучести материала прослойки, на всей длине стыка (рис. 4, б).

Соответственно распределены и пластические деформации в прослойке (рис. 5). Эквивалентные пластические деформации на большей части длины стыка постоянны, на уровне от $0,045 \%$ и $0,1 \%$ в вар. 1 и 2 до $0,4 \%$ и $0,45 \%$ в вар. 3 и 4, то есть, существенно увеличиваясь по мере уменьшения предела текучести прослойки и увеличения разности КЛТР прослойки и основного метала. Вблизи наружной кромки стыка они сначала уменьшаются, а затем снова увеличиваются до $0,10 \ldots 0,17$ и $0,57 \ldots 0,64 \%$.
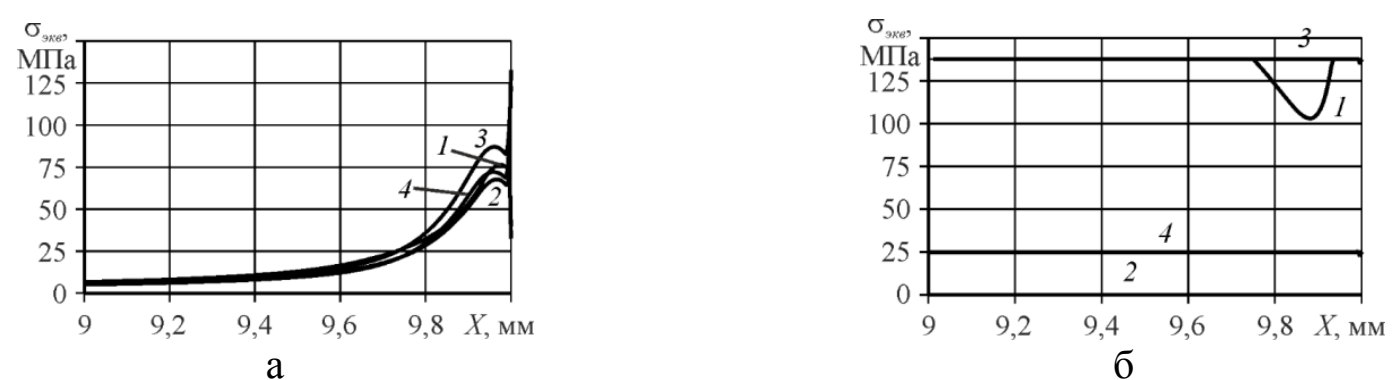

Рис. 4. Эпюры эквивалентных напряжений $\sigma_{\text {экв }}$ по стыку в основном металле (a) и прослойке (б) вблизи его кромки в вариантах 1, 2, 3 и 4
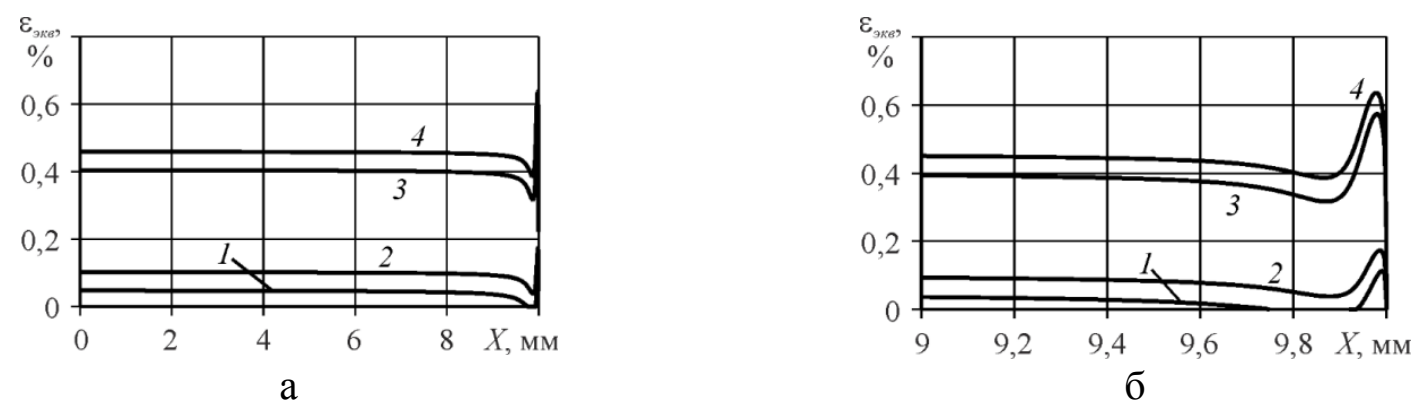

Рис. 5. Эпюры эквивалентных пластических $\varepsilon_{э к в}$ деформаций по стыку в прослойке по всей длине стыка (а) и вблизи его кромки (б) в вариантах узлов 1, 2, 3 и 4

Важной особенностью объемного напряженного состояния по сравнению с линейным является изменение характеристик прочности и пластичности металла (предела текучести и относительного удлинения), относительно определяемых экспериментально при одноосном растяжении. В условиях объемного напряженного состояния происходит упрочнение (повышение прочности и снижение пластичности), что важно с точки зрения повышения прочности соединения, или разупрочнение (снижение прочности и увеличение пластичности), что важно в процессе образования соединения, металла. В качестве количественной характеристики этого изменения используется коэффициент жесткости напряженного состояния, равный отношению максимальных (по модулю) главных напряжений $\left(\sigma_{1}\right.$ или $\left.\sigma_{3}\right)$ к эквивалентным $\sigma_{\text {экв }}$ [12]. Главные и эквивалентные напряжения выдает программа моделирования.

Анализ результатов моделирования НДС при температурном нагружении показал, что появление пластических деформаций в прослойке мало влияет на коэффициент жесткости и степень упрочнения или разупрочнения как основного металла, так и материала прослойки (рис. 6). 
В основном металле вблизи оси узла коэффициент жесткости напряженного состояния равен 0,68, постепенно увеличиваясь по мере приближения к внешней поверхности до 1 на расстоянии около 1 мм от нее и до 1,4...1,6 у самой поверхности. В прослойке он остается равным 1 на большей части длины стыка (90\%) и только у самой поверхности сначала несколько увеличивается (до 1,05), а затем резко снижается до 0,5.
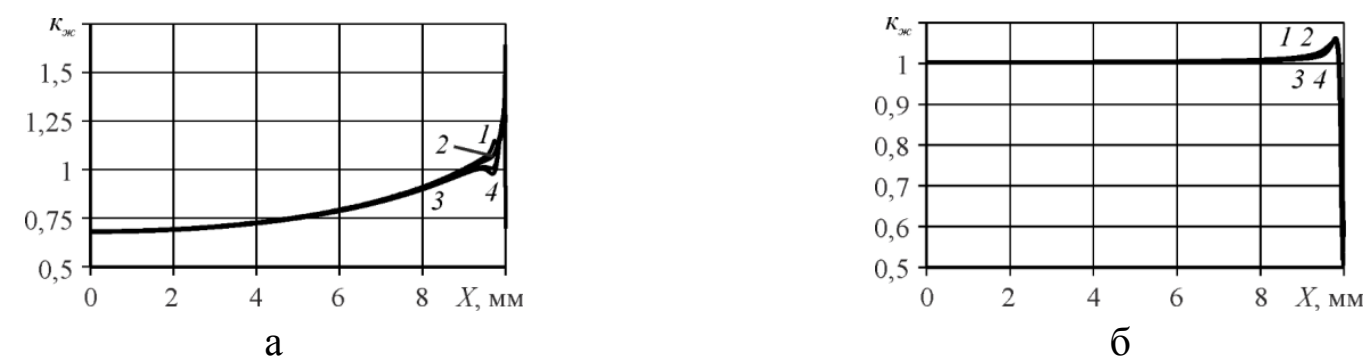

Рис. 6. Изменение коэффициентов жесткости напряженного состояния $\kappa_{\text {ж }}=\sigma_{1(3)} / \sigma_{э к в}$ по стыку в основном металле (а) и прослойке (б) по всей длине стыка (варианты 1, 2, 3 и 4)

Сравнение эпюр с аналогичными в упругой задаче [11] показало, что их характер и уровень как в основном металле, так и в прослойке изменяются незначительно на небольших участках вблизи кромки стыка. Здесь коэффициент жесткости $\kappa_{ж}$ в основном металле увеличивается (металл упрочняется) несколько больше, чем в упругой задаче $(1,35)$. В прослойке он напротив, снижается (металл разупрочняется) так же несколько больше, чем в упругой задаче $(0,6)$.

Таким образом, пластические деформации в прослойке несколько увеличивают эффект упрочнения и разупрочнения основного металла и прослойки на внешней поверхности узла. При этом изменение величины предела текучести и КЛТР прослойки в принятых пределах роли практически не играет.

\section{ВЫВОДЫ}

При термическом нагружении быстрым снижением температуры в цилиндрических узлах из жаропрочного сплава с прослойкой припоя, имеющего КЛТР, меньший или больший сравнительно с основным металлом, а предел текучести ниже, чем у основного металла, появление пластических деформаций не изменяет характер НДС по сравнению с упругим деформированием узла. На большей части узла в основном металле напряжения и деформации отсутствуют. Объемное НДС, обусловленное разностью КЛТР прослойки и основного металла, создается только в прослойке по всей ее длине и на небольших участках, протяженностью не более 10 толщин прослойки, в основном металле вблизи наружной кромки прослойки. На большей части длины прослойки во всех вариантах узлов все составляющие и эквивалентные напряжения и деформации распределены равномерно (постоянны), заметно изменяясь только на небольшом участке вблизи наружной поверхности протяженностью около 10 толщин прослойки.

Изменение соотношения величин КЛТР прослойки и основного металла не влияет на характер НДС, изменяя только знак и уровень напряжений и деформаций. При этом понижение или повышение КЛТР прослойки по сравнению с основным металлом дает противоположные знаки составляющих напряжений, а с ростом абсолютной величины их разности растет уровень напряжений и деформаций. Изменение предела текучести прослойки не влияет на характер НДС, изменяется только уровень напряжений и деформаций. При этом чем меньше предел текучести прослойки по сравнению с основным металлом, тем меньше уровень напряжений в основном металле и больше величина пластических деформаций в прослойке.

Эквивалентные напряжения как в соединяемых материалах, так и в прослойке во всех вариантах на большей части длины стыка сохраняют постоянный уровень. При этом в основном 
металле они практически равны нулю с изменением только в небольшой зоне у кромки стыка. Здесь они резко возрастают, оставаясь ниже его предела текучести. То есть, пластические деформации материала прослойки снижают эквивалентные напряжения в наиболее загруженной зоне основного металла, разгружая и предотвращая пластические деформации в нем.

В вариантах с меньшей разностью КЛТР прослойки и основного металла $\left(10,5 \cdot 10^{-5} 1 /\right.$ град) кратковременные пластические деформации невелики. В вариантах с большей разностью КЛТР прослойки и основного металла $\left(21 \cdot 10^{-5} 1 /\right.$ град) кратковременные пластические деформации заметно увеличиваются.

Появление пластических деформаций в прослойке мало влияет на коэффициент жесткости и степень упрочнения или разупрочнения как основного металла, так и материала прослойки. Как и при упругом нагружении, коэффициент жесткости $\kappa_{ж}$ в основном металле на большей части стыка остается одинаковым во всех вариантах прослоек узлов, увеличиваясь от 0,68 (разупрочнение) на оси узла до 1 по мере приближения к его внешней кромке. У кромки стыка он увеличивается (металл упрочняется) до 1,4...1,6, что несколько больше, чем в упругой задаче $(1,35)$. Разупрочнение металла в средней части стыка при изменении температуры (термоциклировании) должно благоприятно влиять на образование соединения в зоне деформационного застоя при диффузионной сварке. В прослойке у кромки стыка коэффициент жесткости снижается (металл разупрочняется) до 0,5 (в упругой задаче 0,6). При этом изменение величины предела текучести и КЛТР прослойки в принятых пределах роли практически не играют. Разупрочнение основного металла в средней части стыка и прослойки вблизи его кромки необходимо учитывать при конструировании таких узлов и выборе свойств материала прослойки.

\section{СПИСОК ИСПОЛЬЗОВАННОЙ ЛИТЕРАТУРЫ}

1. Спеціальні способи зварювання : підручник / I. В. Крівиун, В. В. Квасницький, С. Ю. Максимов, Г. В. Срмолаєв ; за загальною редакиією академіка НАН Украӥни, доктора технічних наук, професора Б. С. Патона. - Миколаїв : НУК, 2018. - 348 с.

2. Конюшков Г.В. Специальные методы сварки давлением : учебное пособие / Г. В. Конюшков, О. М. Мусин. - Саратов : Ай Пи ЭР медиа, 2009. - 632 с.

3. Паяння матеріалів : підручник / Г. В. Срмолаєв, В. В. Квасницький, В. Ф. Квасницький, С. В. Максимова, В. В. Чигарьов ; за заг. ред. В..Ф. Хорунова і В. Ф. Квасницького. - Миколаїв : НУК, $2015 .-340$ с.

4. Бакши О. А. О напряженном состоянии пластичной прослойки при осимметричной деформации / О. А. Бакии, Л. М. Качанов // Изв. АН СССР, механика. - 1965. - № 2. - С. 134-137.

5. Чигарев A. B. ANSYS для инженеров : Справ. пособ. / А. В. Чигарев, А. С. Кравчук, А. Ф. Смалюк. M. : Машиностроние-10, 2004. - 512 c.

6. Басов К. А. ANSYS : Справочник пользователя / К. А. Басов. - И. : ДМК пресс, 2005. - 640 с.

7. Махненко В. И. Ресурс безопасной эксплуатации сварных соединений и узлов современных конструкций / В. И. Махненко. - Киев : Наукова думка, 2006. - 618 с.

8. Махненко В. И. Особенности формирования напряженно-деформированного состояния соединений разнородных материалов, полученных диффузионной сваркой / В. И. Махненко, В. В. Квасницкий // Автоматическая сварка. - 2009. - № 8. - C. 11-16.

9. Effect of the Rigid interlayer Thickness on the stress-strain of metal-Graphite Assemblies Under Thermal Loading / G. V. Ermolaev, V. A. Martynenko, A. V. Labartkava, M. V. Matvienko // Strenght of Materiale. - may, 2017, Vol. 49. - Issue 3. - P. 422-428.

10. Напряженное состояние сварных и паяных узлов из разнородных материалов с мягкой прослойкой при осевой нагрузке / В. В. Квасницкий, В. Ф. Квасницкий, Dong Chunlin, M. В. Матвиенко, Г. В. Ермолаев // Автоматическая сварка. - 2018. - № 4. - С. 7-13.

11. Компьютерное моделирование напряженно-деформированного состояния в условиях упругости при пайке и диффузионной сварке с прослойками в зависимости от их жесткости / В. В. Квасницкий, В. Ф. Квасниикий, М. В. Матвиенко, Г. В. Ермолаев, Д. М. Голуб // Вісник ДДМА : зб. наук. праць. - Краматорськ : ДДМА, 2019. - № 1 (45). - C. 43-49.

12. Копельман Л. А. Основы теории прочности сварных конструкций: учебное пособие 2-е изд. / Л. А. Копельман. - Санкт-Петербург : Лань, 2010. - 464 с. 